\title{
Herbicidal weed control: benefits and risks
}

\section{Editorial}

Weed causes serious yield loss to different crops by exerting competition with the crops for light, nutrient, moisture and other resources. The removal of weeds by weeding reduces inter-specific competition for resources and enables the crops to utilize available resources more efficiently throughout the growth cycle, which in turns positively influences crop yield and biomass production. Thus, the effective weed management is crucial for higher yield of crop. Manual weeding is generally practiced in many parts of the world as the prime method of weed control. This practice is easy and environment friendly but tedious and highly labour intensive. At present agricultural labour shortage is seen in most of the countries. Moreover, the labour cost is increasing day by day which increases the costs for cultivation making the crop production practice a nonprofitable business venture. Under this situation the herbicide can be used as the most practical and effective alternative means of weed control. Herbicides control weeds very effectively even under the situations where manual and mechanical methods are not applicable. For example, manual or mechanical weeding is delayed in wet soil but herbicides could effectively be used for weed control. Herbicide reduces the cost and drudgery in weed control. Reports show that herbicidal weed control is much cheaper and gives three to four times much more net benefit than manual weed control. Thus weed control by herbicide has clear economic advantages over manual and mechanical weed control. Despite many economic and physical advantages herbicidal weed control may have some adverse effects on wildlife, microbial population, human health and environment. Herbicide may cause phytotoxicity in crop plants and it may aid in herbicide resistance in weeds.

Crop phytotoxicity is often caused due to improper herbicide usage and application techniques. Therefore, application of right herbicide at optimum dose is very important to overcome this phytotoxicity problem. Field trials showed that herbicides such as Pretilachlor, Bispryribac sodium, Propanil, Thiobencarb, Fenoxoprop-p-ethyl, Quinclorac and Bentazon/MCPA did not have any phytotoxic effect on the dry direct seeded rice. Sometimes, slight toxicity may occur with some herbicides but these symptoms would disappear very quickly and cause no serious setback on the growth and yield of the crop. Spray drift of herbicides sometimes cause serious injury to the neighbouring crops that could be overcome by using proper sprayer with due care. Successful control of particular weeds by herbicide often leads to the buildup of another equally serious weed. This type of weed shift is generally caused with the adoption of a single weed control method. Development of herbicide resistance in weed is also a major threat to the herbicidal weed control. The repeated use of same herbicide in a crop field is the principal cause of development of such herbicide resistance. This problem can be easily overcome by rotation of herbicides having different mode of action or by application of herbicide mixtures that enables broad-spectrum weed control. Thus selection of herbicides with different mode of action and their rotation in the weed control in different seasons could be effective in overcoming herbicide resistance problems.

Health hazard to the herbicide spray applicators is caused due to spillage, leakage from spray tanks, splashes during mixing and loading,
Volume 4 Issue 5 - 2016

\author{
Moshiur Rahman \\ Department of Agronomy, Bangladesh Agricultural University, \\ Bangladesh
}

Correspondence: Moshiur Rahman, Department of Agronomy, Bangladesh Agricultural University, Mymensingh-2202,

Bangladesh,Email rahmanag63@yahoo.com

Received: September 29, 2016 | Published: October 05, 2016

dermal absorption of herbicides by soaking by clothes and inhalation of droplets. Many spray operators experience headache, giddiness, skin irritations, skin rashes, vomiting, nail damage, nose bleeding and eye irritation. These health hazards generally occur where spray operators do not follow the safety rules due to their ignorance about the potential hazards and also due to indiscriminate herbicide usages. It should be noted that herbicides are poisonous and must be handled with care. In all cases, applicator should read and consult the label for specific use and handling procedures. Good common sense is always required for herbicide handling and use.

Many studies showed that most herbicides are relatively safe to the user, wildlife, and the environment and are classified as general use pesticides. The reason of this is that the toxic effects of herbicides are relatively specific for plant processes. Most herbicides are subjected to breakdown by microbes, plant tissues and physical processes and are not persist in the soil for long times. Since most herbicides are water soluble and are susceptible to breakdown different processes, so there are little scope of being deposited in the fatty tissues of animals. Most herbicides are relatively low toxic to fish and other aquatic organisms. The soil applied herbicides are adsorbed in the soil colloids and seldom move into water systems. Thus, herbicides applied in the soil have rare chance of polluting water bodies.

The potential toxicity of herbicides to the user is generally expressed in terms of the acute oral dose as measured by $\mathrm{LD}_{50}$. The acute oral toxicity is the dose of herbicide that is taken by mouth or ingested will kill $50 \%$ of the population of the test animal. The herbicide having oral $\mathrm{LD}_{50}$ value of $50 \mathrm{mg} / \mathrm{kg}$ body weight or less is categorized as very high toxic but $\mathrm{LD}_{50}$ value of 50 to 500 is grouped as high toxic, $\mathrm{LD}_{50}$ values from 501 through 5000 is regarded as moderately toxic while herbicides having $\mathrm{LD}_{50}$ values greater than 5000 is considered as low toxic. We know that the $\mathrm{LD}_{50}$ value of table salt is 3320 and that of Aspirin is 1240 while many of the herbicides have the $\mathrm{LD}_{50}$ values higher than table salt and aspirin. Thus, majority of herbicides are less toxic than the table salt or aspirin.

Herbicides applied in the soil are directly exposed to the soil microorganisms. A number of research reports reveal that an initial decline of microbial population was evident just after herbicide application but again the microbial population started to increase and become much more higher than those of the control plots. Thus, it indicates that many herbicides do not have adverse effect 
on microbial population rather it sometimes stimulates microbial growth in the soil. Most of the herbicides applied in the soil do not have longer residual toxicity as they become breakdown with 3 to 7 weeks of application. These herbicides do not affect the germination and growth of the succeeding crops. Therefore, it can be concluded that most of the herbicides are safe for the next crops, if judicious selections of herbicides are being made. Our trials revealed that the growth and yield of the many crops were positively influenced by herbicide treatment.

The available reports show that many of the herbicides are not much more toxic to the wild life, microbial population, human health and environment where judicious application is made and due attention is given. Therefore, herbicide use should be increased for sustaining crop production with minimal cost at the face of recent unavailability of labour. However, necessary steps should be taken to restrict the indiscriminate use of herbicides for ensuring healthy life and environment.

\section{Acknowledgements}

None.

\section{Conflict of interest}

The author declares no conflict of interest. 